\title{
ICSI - A biotechnological method to produce equine embryos in vitro
}

\author{
Hannelore Alm, Andreas Vernunft, Helmut Torner, Sanjay Bhojwani, Frank Becker und Wilhelm Kanitz
}

Research Institute Biology Farm Animals, Unit Reproductive Biology, Dummerstorf, Germany

\begin{abstract}
Summary
Progress in assisted reproduction in the horse has been rapid over the last 10 years. Efficient methods for oocyte recovery from live mares have generated clinical interest in methods for in vitro fertilization (IVF). The conventional method of IVF as used in the bovine has proved to be inefficient in the horse. Therefore, a method for more efficient production of equine zygotes has been developed - the intracytoplasmic sperm injection (ICSI). The aim of our investigation was to establish this method in our laboratory and to test its efficiency in generating developmentally competent equine embryos. Altogether, 146 COCs with different cumulus morphology were recovered. The polar body extrusion rate after IVM was between 48 and $64 \%$ depending on the cumulus morphology and the maturation time. The cleavage rate after ICSI was between $40 \%$ and $47 \%$. Under the chosen in vitro conditions, we could obtain 16 cell stage embryos and morulae on day 5 after ICSI.
\end{abstract}

Keywords: mare, reproduction, IVM, ICSI, embryonic development

\section{ICSI - Eine Biotechnik zur Erzeugung von Embryonen in vitro}

Assistierende Reproduktionstechniken beim Pferd haben sich in den letzten 10 Jahren dynamisch entwickelt. Effiziente Methoden der Oozytengewinnung von lebenden Stuten haben das klinische Interesse an Methoden der IVF geweckt. Die konventionelle Methode der IVF, wie sie beim Rind bereits kommerziell angewendet wird, hat sich als ineffizient bei der Spezies Pferd herausgestellt. Deshalb wurde eine Methode zur effizienteren Erzeugung von Stutenembryonen entwickelt - die Intracytoplasmatische Spermieninjektion, kurz ICSI. Das Ziel der vorliegenden Untersuchungen war es, diese Methode in unserem Labor zu etablieren, und ihre Effizienz zur Erzeugung entwicklungsfähiger Embryonen unter unseren Bedingungen zu testen. Insgesamt wurden 146 Cumulus-Oozyten-Komplexe mit unterschiedlicher Cumulusmorphologie gewonnen. Die Ausschleusung des Polkörperchen, ein Beweis für eine erfolgreiche in vitro Reifung (IVM), war bei 48 bzw. 64\% der Oozyten nachzuweisen. Die Furchungsrate nach ICSI betrug 40 bzw. 47\%. Unter den gewählten Bedingungen konnten sich die nach ICSI erzeugten Embryonen bis zum Stadium der Morula entwickeln.

Schlüsselwörter: Stute, Reproduktion, IVM, ICSI, Embryonenentwicklung

\section{Introduction}

Development of assisted reproductive technologies in horses has been slow compared to other domestic animals, like ruminants and pigs. Not only the scarce availability of oocyte, but also the lacks of interest from horse breeders have been the main reason for this delay. In the last few years there has been increasing interest in obtaining foals via assisted reproduction from mares. Efficient methods for oocyte recovery from live mares have generated clinical interest in methods for in vitro fertilization (IVF). The conventional method of IVF (maturation of oocytes, culture of oocytes with capacitated sperm, cultivation of zygotes), as used in the bovine, has proved to be inefficient in the horse (Alm et al. 2001). Therefore, a method for more efficient production of equine embryos has been developed - the intracytoplasmic sperm injection (ICSI). With ICSI, one spermatozoon is injected into a mature oocyte. Equine embryos produced by in vitro maturation, ICSI, in vitro embryo culture and transferred transcervically to recipient mares have resulted in the birth of normal foals. Fertilized equine oocytes, produced by ICSI, are also being used to develop effective equine embryo culture systems.

The first foal after ICSI was born in the USA (Squires et al. 1996). The authors injected in vitro matured oocytes with sperm, and transferred them to the oviducts of recipient mares. They obtained one pregnancy that was carried to term. In the following years this result could not be repeated. The cleavage rates were low after ICSI and it was not possible to obtain blastocyst stages. The use of a Piezo micromanipulator increased both the activation of the oocytes and the cleavage rates (Choi et al. 2002, Galli et al. 2002). The vibration in the injection pipette caused by the Piezo drill did not only facilitate the penetration of the zona pellucida, but also ensured the breakage of the sperm membrane and the ooplasm membrane.

The primary aim of using the Piezo drill to perform ICSI was to get cleaved embryos. Embryo culture was initially performed in vivo, in the mare oviduct or in the surrogate sheep oviduct. With these methods it was possible to obtain 18 to $36 \%$ cleaved embryos (Galli et al. 2002). Choi et al. (2002) obtained about $80 \%$ cleavage rate with embryos of $>8$ cell within $96 \mathrm{~h}$ of in vitro culture. New culture methods were necessary to develop to culture the fertilized early embryonic stages to blastocysts, which could be transferred directly to the uterus. Several investigations were carried out to improve the blastocyst formation in vitro. The effect of medium-toembryo ratio (Choi et al. 2007) and comparison of culture 
media (Hinrichs et al. 2007) led to better blastocyst development.

The aim of our investigation was to establish this method of ICSI in our laboratory and to test its efficiency in generating developmentally competent and transferable equine embryos leading to pregnancies.

\section{Materials and Methods}

Cumulus oocyte complexes (COCs) were obtained by ovum pick-up (OPU) in Mecklenburger Warmblood mares which underwent repeated (once per week) transvaginal ultrasoundguided follicle aspiration. After aspiration the COCs were evaluated and, according to their cumulus morphology, in vitro matured. COCs with expanded cumulus and corona radiata cells were incubated for $24 \mathrm{~h}$, while those with compact cumulus were matured for 30 to $32 \mathrm{~h}$. After the in vitro maturation (IVM), the oocytes were denuded by gentle pipetting and the matured oocytes [oocytes with extruded polar body (PB)] were used in the experiment.

Simultaneously, frozen-thawed sperm were prepared for the ICSI procedure. Semen straws were thawed at $39^{\circ} \mathrm{C}$ in a water bath for $30 \mathrm{~s}$ and $200 \mu \mathrm{l}$ of semen was placed at the bottom of a tube containing $1 \mathrm{ml} \mathrm{Sp-CZB} \mathrm{(Choi} \mathrm{et} \mathrm{al.} \mathrm{2003)}$ for swim up. After 20 min incubation at $38.5^{\circ} \mathrm{C}, 600 \mu \mathrm{l}$ of medium was collected from the top of the tube and centrifuged at $327 \times \mathrm{g}$ for $3 \mathrm{~min}$. Then the sperm pellet was resuspended and washed once with the same medium.

For the ICSI procedure, a Piezo injection system was used. For holding oocytes, a $120 \mu \mathrm{m}$ (o.d.) pipette was used. The injection pipette had an inner diameter of $5 \mu \mathrm{m}$. Immediately before injection, $1 \mu$ sperm suspension was placed in a small drop of Sp-CZB containing 10\% PVP. Spermatozoa were immobilized by applying a few pulses with a Piezo drill to the tail, and were aspirated in the injection pipette (Fig. 1). A small pulse was generated by the Piezo apparatus to assist the smooth passage of the injection pipette through the zona pellucida of the oocyte. Before setting up a sper- matozoon in the oocyte, a reduced pulse was given using the Piezo drill to ensure breakage of the oolemma following which the sperm was slowly released in the oocyte cytoplasm and the injection pipette slowly exited. Injected oocytes were cultured in DMEM/F-12 for 5 to 6 days to generate transferable embryos.

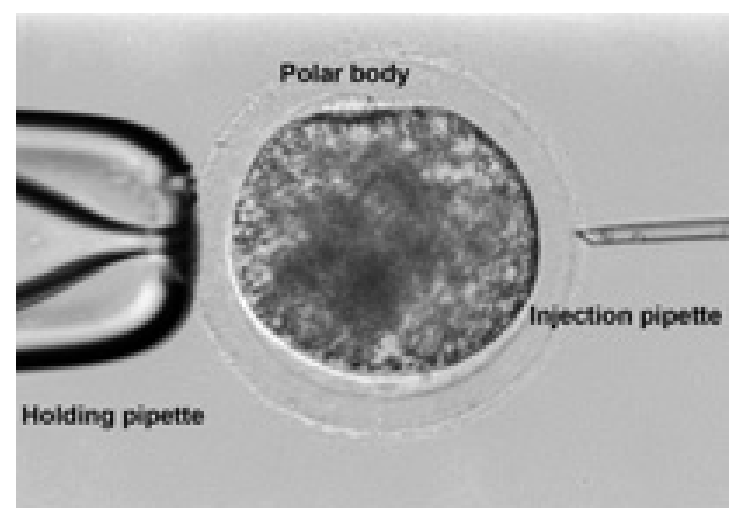

Fig. 1 ICSI in horse oocyte / ICSI in Stutenoozyte

\section{Results and Discussion}

Altogether, $146 \mathrm{COCs}$ with different cumulus morphology were recovered. The mean recovery rate was $22.8 \%$ (18.5 - 45.5). The comparatively low recovery rate can be explained by the fact that the equine oocyte is rather firmly connected to the follicular wall than in other species. The closer and broader attachment of equine cumulus to the follicular wall, the greater integrity of the cumulus, and the extension of cumulus cell processes into the thecal pad may prevent the equine $\mathrm{COC}$ from being aspirated from the follicle (Hawley et al. 1995).

The polar body extrusion rate was between 48 and $64 \%$ depending on the cumulus morphology and the maturation time (Table 1). The maturation rate is in agreement with data from other experimental laboratories engaged in the field of equine ICSI where polar body extrusion rates of about $63 \%$ (Choi et al. 2004) and 60\% (Galli et al. 2007) were reported.

Table 1 IVM of horse oocytes after OPU / Invitroreifung von Pferdeoozyten nach Ovum-pick-up., PB = Polar Body

\begin{tabular}{cccc}
\hline COC morphology & n oocytes & Time of IVM (h) & n oocytes with PB (\%) \\
\hline compact & 35 & $30-32$ & $17(48.6)$ \\
expanded & 14 & $22-24$ & $9(64.3)$ \\
corona radiata & 97 & $22-26$ & $57(58.8)$ \\
\hline
\end{tabular}

Table $2 \mathrm{ICSI}$ in horse oocytes after OPU and IVM / Intracytoplasmatische Spermieninjektion in eine Pferdeoozyte nach Ovum-pick-up und Invitroreifung. PB $=$ Polar Body

\begin{tabular}{|c|c|c|c|}
\hline COC morphology & n oocyten & Cleavage, n (\%) & Stage of developmen \\
\hline \multicolumn{4}{|l|}{ Compact } \\
\hline$+\mathrm{PB}$ & 17 & $8(47.1)$ & IX cell stage \\
\hline$-\mathrm{PB}$ & 18 & 0 & \\
\hline \multicolumn{4}{|l|}{ expanded or corona radiata } \\
\hline$+\mathrm{PB}$ & 62 & $25(40.3)$ & Morula (32 cells) \\
\hline$-\mathrm{PB}$ & 41 & $5(12.2)$ & $\mathrm{XVI}$ cell stage \\
\hline
\end{tabular}


The first foal after ICSI was born in the USA (Squires et al. 1996). In the following years this result could not be repeated. The cleavage rates were low after ICSI and it was not possible to obtain blastocyst stages. The use of a Piezo micromanipulator increased both the activation of the oocytes and the cleavage rates (Choi et al. 2002, Galli et al. 2002).
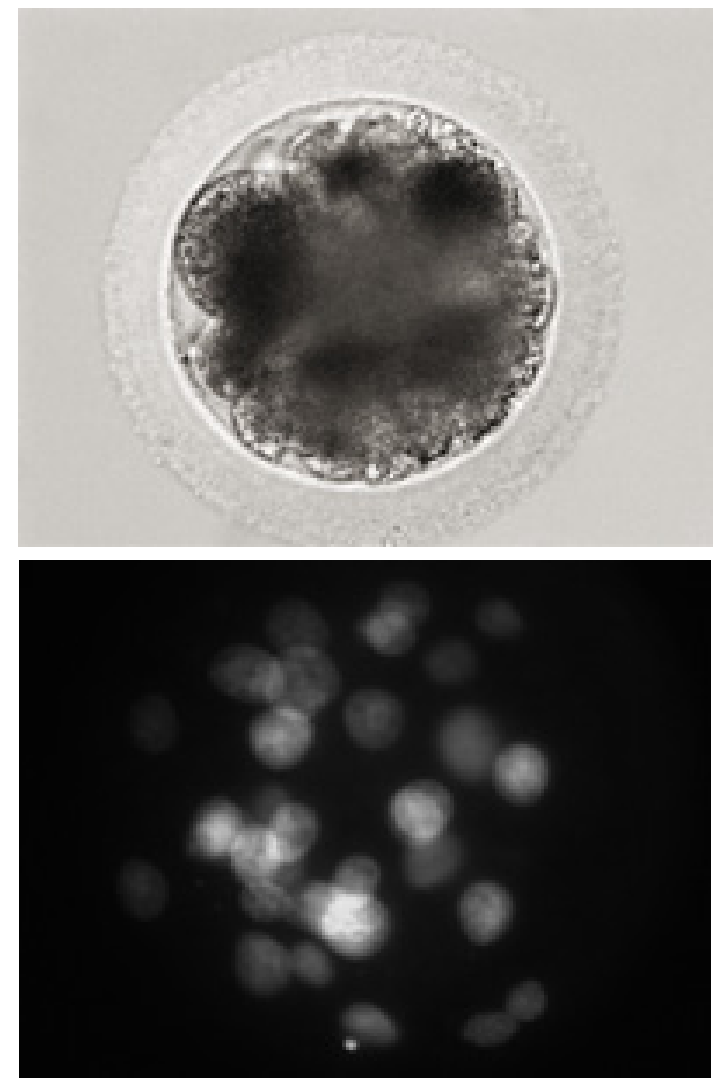

Fig. 2 Horse embryos: 12-cell stage (above); morula, 32 cells (below)

Pferdeembryonen: 12-Zell-Embryo (oben); Morula, 32 Zellen (unten)

In the present results we could obtain between $40 \%$ and $47 \%$ of cleavage rates after sperm injection. Under the chosen in vitro conditions, we could obtain 16-cell stage embryos and morulae on day 5 after ICSI (Table 2, Figure 2).

The development up to the blastocyst stage, which could be transferred transvaginally, was very low at the beginning. Good results could be obtained when the injected oocytes (Choi et al. 2004) or early embryonic stages (Galli et al. 2002) were transferred into the oviduct of the mare or sheep for a "mid-culture".

The development of new culture media in the last years led to development of blastocysts in a complete in vitro system (Choi et al. 2006, Hinrichs et al. 2007, Galli et al. 2007).

Our present results indicate that the production of equine embryos in vitro using the method of intracytoplasmic sperm injection is, in principle, possible in our lab. The results are promising; however, much needs to be done to improve the current cleavage rates of the equine ICSI embryos. Also the- re is an urgent need to optimize culture systems for ICSIgenerated equine embryos in order to achieve high blastocyst development rates. In the future, only embryo transfer would be able to reveal the efficiency of such blastocysts to generate acceptable pregnancy and foaling rates.

\section{References}

Alm H., Torner H., Blottner S., Nuernberg G. and Kanitz W. (2001) Effect of sperm cryopreservation and treatment with calcium ionophore or heparin on in vitro fertilization of horse oocytes. Theriogenol. 56, 817-829.

Choi Y. H., Love C. C., Varner D. D. and Hinrichs K. (2006) Equine blastocyst development after ISCl of sperm subjected to two freeze-thaw cycles. Theriogenol. 65, 808-819

Choi Y. H., Love C. C., Varner D. D. and Hinrichs K. (2007) Effect of holding technique and culture drop size in individual or group culture on blastocyst development after ICSI of equine oocytes with low meiotic competence. Anim. Reprod. Sci. 102, 38-47

Choi Y. H., Chung Y. G., Walker S. C., Westhusin M. E. and Hinrichs K. (2003) In vitro development of equine nuclear transfer embryos: effect of oocyte maturation media and amino acid composition during embryo culture. Zygote 1 1, 77-86

Choi Y. H., Love C. C., Love L. B., Varner D. D., Brinsko S. P. and Hinrichs K. (2002) Developmental competence in vivo and in vitro of in vitro matured equine oocytes fertilized by Intracytoplasmic sperm injection with fresh or frozen-thawed sperm. Reproduction 123, 455-465

Choi Y. H., Roasa L. M., Love C. C., Varner D. D., Brinsko S. P. and Hinrichs K. (2004) Blastocyst Formation rates in vivo and in vitro of in vitro matured equine oocytes fertilized by Intracytoplasmic sperm injection. Biol. Reprd. 70, 1231-1238

Galli C., Crotti G., Turini R., Duchi R., Mari G., Zavaglia G. et al. (2002) Frozen-thawed embryos produced by ovum pick up of immature oocytes and ICSI are capable to establish pregnancies in the horse. Theriogenol. 58, 705-708 (abstr)

Galli C., Colleoni S., Duchi R., Lagutina I. and Lazarri G. (2007) Developmental competence of equine oocytes and embryos obtained by in vitro procedures ranging from in vitro maturation and ICSI to embryo culture, cryopreservation and somatic cell nuclear transfer. Anim. Reprod. Sci. 98, 39-55

Hawley L. R., Enders A. C. and Hinrichs K. (1995) Comparison of equine and bovine oocyte-cumulus morphology within the ovarian follicle. Biol. Reprod. Mono. 1, 243-252

Hinrichs K., Choi Y. H., Walckenaer B. E., Varner D. D. and Hartman D. L. (2007) In vitro produced equine embryos: Production of foals after transfer, assessment by differencial staining and effect of medium calcium concentration during culture. Theriogenol. 68, 521-529

Squires E. L., Wilson J. M., Kato H. and Blaszczyk A. (1996) A pregnancy after intracytoplasmic sperm injection into equine oocytes matured in vitro. Theriogenol. 45, 306 (abstr).
Dr. Hannelore Alm

Research Institute Biology Farm Animals

Unit Reproductive Biology

18196 Dummerstorf, Germany

alm@fbn-dummerstorf.de 